\title{
Gonococcal Tysonitis without urethritis after prophylactic post-coital urination
}

\author{
J. A. BURGESS \\ Clayton Hospital, Wakefield, Yorkshire
}

This case of gonococcal Tysonitis, without preceding or concomitant urethritis, is described mainly because the patient deliberately used post-coital urination as a method of trying to prevent venereal disease.

\section{Case report}

A 44-year-old married man attended a venereal diseases clinic complaining of discomfort in the penis of 5 days' duration. He said that he seldom had intercourse with his wife because of her chronic ill-health; but he admitted to frequent extramarital sexual relationships over many years with casual acquaintances and prostitutes. The last exposure to sexual infection had been intercourse with a prostitute 9 days before attending.

PREvious HISTORY He had attended the same clinic 3 years previously suffering from acute gonorrhoea, which was treated and cured by an injection of penicillin.

EXAMINATION AND TREATMENT There was a small tender swelling at the left side of the fraenum and pus was expressed from the left Tyson's duct. A Gram-stained smear of the pus showed typical intracellular Gramnegative diplococci and gonococci were grown on culture. There were no signs of urethritis and both specimens of urine in the 2-glass test were clear and free from threads.

$\mathrm{He}$ was treated with a single injection of $1.25 \mathrm{~m}$.u. penicillin $(0.5 \mathrm{~m}$.u. each of benzyl and procaine penicillin plus 0.25 m.u. benethamine penicillin), and 4 days later the Tyson's abscess had subsided and again there were no signs of urethritis or pyuria.

He remained under observation for 3 months, and during this time tests of cure, including repeated examination of the urine and prostatic secretion, all gave negative results. FURTHER HISTORY In view of the unusual finding of gonococcal Tysonitis without preceding or concomitant urethritis, the patient was asked for more information about his sexual behaviour. He said that when he was in the army about 25 years previously, a lecturer on hygiene had advised the audience of soldiers always to pass urine immediately after sexual intercourse. He had usually tried to carry out this advice but occasionally found that he was unable to pass urine or was too befuddled by alcohol to remember to do so. On one such occasion 3 years previously he had contracted gonorrhoea.

Paper read to the MSSVD on May 15, 1970

Received for publication June 15, 1970
Comment

Gonococcal Tysonitis is an uncommon complication of gonorrhoea. It is even less commonly encountered as an isolated finding without preceding or concomitant gonococcal urethritis.

The hypothesis relating to post-coital urination as a prophylactic method for males is that by passing urine within a few minutes after ejaculation any gonococci or other pathogens which have entered the urethra during coitus are flushed out before they have had time to become established on and in the urethral mucous membrane.

In considering prophylactic post-coital urination, there are at least three questions which require discussion:

(1) Does post-coital urination have any prophylactic value? A search of the literature has produced little information. Arya and Bennett (1968) included urination after sexual contact as one of the items of knowledge of prophylactic measures of venereal disease. Bennett (1968) wrote that some students in Uganda thought that urination helped to prevent gonorrhoea but the details were not clear. Willcox (1964) recommended that after intercourse a man should urinate, preferably in short sharp gushes, the mechanical effect of which was to flush the urethra.

Bernfeld (1961), in a comprehensive survey of the literature on gonorrhoea of the median raphé of the penis, reported that in 46 of the 63 certain cases, the urethra was expressly said to be free from infection. Mills (1924) described a case of gonococcal infection of a sebaceous follicle of the prepuce in which there was no concomitant urethritis. Whether any of these males practised post-coital urination was not stated. (2) Assuming that post-coital urination is a prophylactic procedure to be recommended, what is the maximum effective interval of time between ejaculation and urination? From information given by three patients (including the one mentioned in this paper), all of whom believed that they avoided attacks of urethritis by post-coital urination, the time between ejaculation and urination was thought to be 
about 2 to 3 minutes. The vital time is probably very short-the maximum effective time between ejaculation and urination may be three minutes or less. (3) What is the minimum volume of fluid required to flush the urethra? Gonorrhoea can certainly arise in males who use coitus interruptus as a method of contraception, and it would seem that 2 or $3 \mathrm{ml}$. of semen are insufficient to remove gonococci from the urethra during ejaculation. The capacity of the average anterior urethra is $10 \mathrm{ml}$. (Pelouze, 1939) and the 2-glass test indicates that the volume of urine required to flush the anterior urethra is in the region of 50 to $100 \mathrm{ml}$.

Many of the above remarks are necessarily speculative but it would seem that post-coital urination deserves further investigation as a harmless and simple method of preventing some cases of urethritis.

\section{Summary}

A case is described of gonococcal Tysonitis without preceding or concomitant urethritis. The patient $\overrightarrow{\vec{N}}$ deliberately passed urine immediately after extra- marital coitus in attempting to prevent venereal disease, and by this method he was apparently suc- $\overline{\bar{\rho}}$ cessful on many occasions in preventing attacks of $\bar{\nabla}$ urethritis. The possible value of post-coital urination $\frac{2}{0}$ for prophylaxis is discussed and the suggestion made os that it deserves further investigation.

\section{References}

ARYA, O. P. and BenNetT, F. J. (1968) Brit. F. vener. Dis., 44, 160

Bennett, F. J. (Oct., 1968) Personal communication

BERNFELD, W. K. (1961) Brit. F. vener. Dis., 37, 210

Mills, C. (1924) Lancet, 1, 1158

Pelouze, P. S. (1939) 'Gonorrhea in the Male and Female', 3rd ed., p. 23. Saunders, Philadelphia

Willcox, R. R. (1964) 'Textbook of Venereal Diseases $\mathbb{Q}$ and Treponematoses', 2nd ed., p. 428. Heinemann Medical Books, London 